NOTE

\title{
Synthesis and Reactions of Polycarbonate with Pendant Vinyl Groups
}

\author{
Yasuhiko YoshIDA, Atsuko NishiYAmA, \\ and Shohei INOUE \\ Department of Synthetic Chemistry, Faculty of Engineering, \\ The University of Tokyo, Bunkyo-ku, Tokyo 113, Japan.
}

(Received December 23, 1981)

\begin{abstract}
KEY WORDS Carbon Dioxide / Butadiene Monoxide / Copolymerization / Polycarbonate / Bromination / Epoxide /
\end{abstract}

The alternating copolymerization of carbon dioxide and epoxide gives an aliphatic polycarbonate with high molecular weight. ${ }^{1,2}$ This copolymerization reaction is general for epoxide; unsubstituted, monosubstituted, and disubstituted. ${ }^{1,3}$ However, few examples have been reported for the synthesis of carbon dioxide-epoxide copolymer with functional pendant groups. We reported that a polycarbonate having hydroxyl groups can be synthesized via the copolymerization of trimethylsilyl glycidyl ether and carbon dioxide. ${ }^{4}$

The present article describes some of the results of our study on the application of the carbon dioxide-epoxide copolymer as a degradable functional polymer. The copolymerization of carbon dioxide and epoxide having a vinyl group was carried out, and the introduction of various functional groups into the copolymer thus obtained was examined utilizing the pendant groups.

\section{EXPERIMENTAL}

\section{Materials}

Butadiene monoxide (BMO) was prepared from butadiene through the bromohydrin according to the method reported by Winstein and Lucas. $^{5}$ Epoxides were dried and distilled over calcium hydride in nitrogen atmosphere. Commercial high purity carbon dioxide gas was used without further purification.

\section{Copolymerization}

Copolymerization was carried out using a diethylzinc-water $(1: 0.9)$ system as the catalyst in a stainless autoclave, as reported previously for the copolymerization of propylene oxide with carbon dioxide. ${ }^{6}$ The reaction mixture was diluted with benzene, and washed with $1 N$ hydrochloric acid and then with water. The benzene layer containing the copolymer was added to methanol with stirring. The precipitated white copolymer was collected by filtration and then was freeze-dried from benzene solution.

Analysis for BMO- $\mathrm{CO}_{2}$ copolymer: Calcd for $\mathrm{C}_{5} \mathrm{H}_{6} \mathrm{O}_{3}: \mathrm{C}, 52.63 \%$; $\mathrm{H}, 5.30 \%$. Found: $\mathrm{C}, 53.24 \%$, $\mathrm{H} ; 5.97 \%$.

\section{Bromination of $\mathrm{BMO}-\mathrm{CO}_{2}$ Copolymer}

For example, butadiene monoxide-carbon dioxide copolymer (BMO- $\mathrm{CO}_{2}$ copolymer) $(0.5 \mathrm{~g})$ was dissolved in chloroform $(100 \mathrm{ml})$ in a flask fitted with a magnetic stirrer. To the solution was added bromine $(0.4 \mathrm{~g})$ and the mixture was stirred for $150 \mathrm{~min}$ at room temperature. The reaction mixture was then concentrated and poured with stirring into methanol. The white precipitate was collected and dried; yield, $0.26 \mathrm{~g}$.

Reaction of $\mathrm{BMO}-\mathrm{CO}_{2}$ Copolymer and transDichloro(pyridine)(ethylene)platinum (II)

About $500 \mathrm{mg}$ of $\mathrm{PtCl}_{2}\left(\mathrm{C}_{2} \mathrm{H}_{4}\right) \mathrm{Py}^{7,8}$ was added to a solution $(30 \mathrm{ml})$ of $\mathrm{BMO}-\mathrm{CO}_{2}$ copolymer $(150 \mathrm{mg})$ in chloroform and the mixture was stirred 
at room temperature. After $3 \mathrm{~h}$, the precipitation of brown powder was observed. The mixture was evaporated to dryness under reduced pressure. The solid residue was washed several times with chloroform to give an insoluble product; yield, $200 \mathrm{mg}$. Anal. Calcd for $\left(\mathrm{C}_{10} \mathrm{H}_{11} \mathrm{Cl}_{2} \mathrm{NO}_{3} \mathrm{Pt}\right)_{x}$ i.e., $\{\mathrm{O}-\mathrm{CO}-\mathrm{O}-$ $\left.\mathrm{CH}_{2} \mathrm{CH}\left[\left(\mathrm{CH}=\mathrm{CH}_{2}\right) \mathrm{PtCl}_{2}\left(\mathrm{C}_{5} \mathrm{H}_{5} \mathrm{~N}\right)\right]\right\}_{x}: \mathrm{C}, 26.16 \%$; $\mathrm{H}, 2.42 \% ; \mathrm{Cl}, 15.44 \%$; N $3.05 \%$ : Ash, $45.97 \%$. Found: C, $25.12 \% ; \mathrm{H}, 2.65 \% ; \mathrm{Cl}, 17.38 \%$; N, $2.87 \%$; Ash, $45.74 \%$.

\section{Analyses}

Gel permeation chromatogram (GPC) was registered on a Toyo Soda high speed liquid chromatograph (model HLC 802 UR) equipped with four columns of porosity ratings $7000-3000 \AA$ (two), $3000 \AA$ (one ) and $2000 \AA$ (one). The average molecular weight was determined from the GPC curve on the basis of the calibration curve obtained by using standard polystyrene.

\section{RESULTS AND DISCUSSION}

Synthesis of Polycarbonates with Pendant Vinyl Groups<smiles>C=CC(CC)OC(=O)O[18C](Br)Br</smiles>

Table 1. Copolymerization of carbon dioxide and butadiene monoxide ${ }^{a}$

\begin{tabular}{|c|c|c|c|c|c|c|}
\hline \multicolumn{2}{|c|}{ Epoxide $^{b}$} & \multirow{3}{*}{$\begin{array}{l}\text { Time } \\
\text { days }\end{array}$} & \multicolumn{4}{|c|}{ Copolymer } \\
\hline $\mathbf{M}_{1}$ & $\mathrm{M}_{2}$ & & Yield $^{c}$ & $f_{\mathrm{CO}_{2}}{ }^{\mathrm{d}, \mathrm{e}}$ & $\mathrm{M}_{1} / \mathrm{M}_{2}^{\mathrm{e}}$ & {$[\eta]^{\mathrm{f}}$} \\
\hline g & g & & g & $\mathrm{mol}^{\circ} \%$ & mole ratio & $10^{2} \mathrm{~cm}^{3} \mathrm{~g}^{-1}$ \\
\hline BMO (8.8) & - & 4 & 5.9 & 49 & - & 1.52 \\
\hline BMO (4.4) & PO (3.6) & 5 & 3.7 & 50 & 0.56 & 1.41 \\
\hline
\end{tabular}

a Catalyst, $\mathrm{ZnEt}_{2}-\mathrm{H}_{2} \mathrm{O}(1: 0.9), 14 \mathrm{~mol} \%$ with respect to epoxide; solvent, 1,4-dioxane (40 ml); $\mathrm{CO}_{2}$ pressure, 40 atm (SI-unit : $1 \mathrm{~atm}=101,325 \mathrm{KN} \cdot \mathrm{m}^{-2}$ ); temperature, $35^{\circ} \mathrm{C}$.

${ }^{b}$ Epoxide; BMO, butadiene monoxide; PO, propylene oxide. $\mathbf{M}_{1}$ and $\mathbf{M}_{2}$, equimolar amount.

c Methanol-insoluble portion.

d Amount of $\mathrm{CO}_{2}$ (oxycarbonyl-groups content) in the copolymer.

e Determined by ${ }^{1} \mathrm{H}$ NMR spectra.

${ }^{f}$ Measured at $30^{\circ} \mathrm{C}$ in benzene solution. 
The ${ }^{1} \mathrm{H}$ NMR spectra of the starting copolymer and that of the reaction product (Figure 1) confirmed the successful bromination of the polycarbonate. In the ${ }^{1} \mathrm{H}$ NMR spectrum of $\mathrm{BMO}-\mathrm{CO}_{2}$ copolymer (Figure 1, A), the peaks at $3.8-4.4 \mathrm{ppm}$, $5.0-5.5 \mathrm{ppm}$, and $5.5-6.0 \mathrm{ppm}$ were assigned to oxymethylene groups (a), an overlap of oxymethine (b) and methylene groups on the side chain (d), and methine groups on the side chain (c), respectively. In the spectrum of the reaction product with bromine, a new signal appeared at $3.5-4.0 \mathrm{ppm}(\mathrm{h})$, demonstrating formation of a bromomethyl group $\left(-\mathrm{CH}_{2} \mathrm{Br}\right.$ ) (Figure 1, B). The extent of bromination was determined by a comparison of the signal intensities of the methylene proton in bromomethyl group (h) with that of the methine proton in the unreacted vinyl group (c).

Additional confirmation of the successful bromination of the polycarbonate was provided by IR spectra, in which the band due to the stretching vibrations of the vinyl groups present in the starting copolymer at $1640 \mathrm{~cm}^{-1}$ was reduced in the reaction product.

The extent of bromination of $\mathrm{BMO}-\mathrm{CO}_{2}$ copolymer increased with prolonged reaction time and with an increase in the amount of bromine reacted (Table II). However, in the reaction involv-

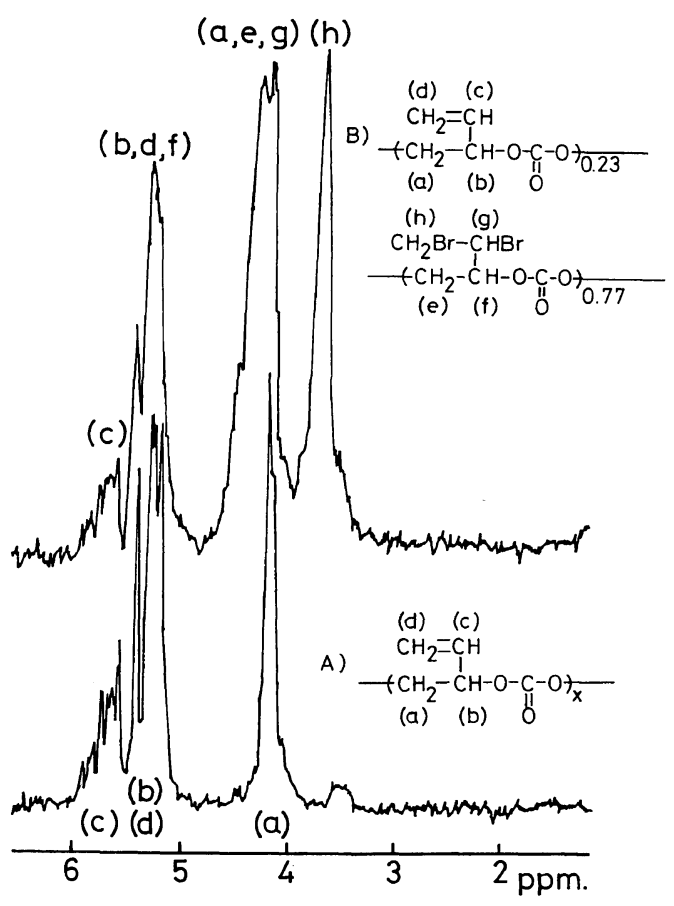

Figure 1. ${ }^{1} \mathrm{H}$ NMR spectra of A) Butadiene monoxide-carbon dioxide copolymer, and B) Brominated BMO- $\mathrm{CO}_{2}$ copolymer (Table II, Run 4); in $\mathrm{CDCl}_{3}$.

Table II. Addition of bromine to butadiene monoxide-carbon dioxide copolymer (BMO- $\mathrm{CO}_{2}$ copolymer) ${ }^{\mathrm{a}}$

\begin{tabular}{|c|c|c|c|c|c|c|c|}
\hline \multirow{4}{*}{ Run } & \multirow{4}{*}{$\frac{\begin{array}{c}\mathrm{BMO}-\mathrm{CO}_{2} \\
\text { Copolymer }\end{array}}{\mathrm{g}}$} & \multirow{4}{*}{$\frac{\text { Bromine }}{\mathrm{g}\left(\mathrm{mol}^{\mathrm{o}} \mathrm{o}\right)^{\mathrm{c}}}$} & \multirow{4}{*}{$\frac{\text { Time }}{h}$} & \multicolumn{4}{|c|}{ Product } \\
\hline & & & & \multirow{3}{*}{$\frac{\text { Yield }^{\mathrm{d}}}{\mathrm{g}}$} & \multicolumn{2}{|c|}{ Extent of bromination ${ }^{\mathrm{e}}$} & \multirow{3}{*}{$M_{\mathrm{GPC}} \times 10^{-4 \mathrm{f}}$} \\
\hline & & & & & \multirow{2}{*}{$\frac{{ }^{1} \mathrm{H} \text { NMR }}{\mathrm{mol}^{\mathrm{o}} \%}$} & \multirow{2}{*}{$\begin{array}{c}\text { E.A. } \\
\mathrm{mol} \%\end{array}$} & \\
\hline & & & & & & & \\
\hline 1 & 0.5 & $0.4(50)$ & 2.5 & 0.26 & 26 & 26 & $2.5^{\mathrm{g}}$ \\
\hline 2 & 0.5 & $0.4(50)$ & 12 & 0.40 & 34 & 40 & 1.1 \\
\hline 3 & 1.1 & $1.6(100)$ & 60 & 1.10 & 77 & 56 & 0.55 \\
\hline 4 & 1.1 & $1.6(100)$ & 260 & 0.85 & 77 & 56 & $0.45^{\mathrm{h}}$ \\
\hline 5 & 0.5 & $1.6(200)$ & 27 & 0.30 & 100 & - & 0.27 \\
\hline
\end{tabular}

a In chloroform at room temperature.

b $M_{\mathrm{GPC}}=10 \times 10^{4},[\eta]=1.28 \times 10^{2} \mathrm{~cm}^{3} \mathrm{~g}^{-1}$ (measured at $30^{\circ} \mathrm{C}$ in benzene solution).

c $\mathrm{Mol} \%$ with respect to carbon-carbon double bond.

d Methanol insoluble portion.

e Determined by ${ }^{1} \mathrm{H}$ NMR spectra and elementary analyses (E.A.), respectively.

f On the basis of the calibration curve obtained by using standard polystyrene.

g $[\eta]=0.11 \times 10^{2} \mathrm{~cm}^{3} \mathrm{~g}^{-1}$ (measured at $30^{\circ} \mathrm{C}$ in benzene solution).

${ }^{\mathrm{h}} M_{n}=0.53 \times 10^{4}$ (measured in benzene solution by a vapor pressure osmometer). 
ing a large amount of bromine, the amount of bromine in the product from elemental analysis was not in good agreement with the calculated value from ${ }^{1} \mathrm{H}$ NMR spectrum, probably as a result of certain side reactions. The molecular weight of the brominated $\mathrm{BMO}-\mathrm{CO}_{2}$ copolymer, as determined by gel permeation chromatography $\left(M_{\mathrm{GPC}}\right)$, significantly decreased from that of $\mathrm{BMO}-\mathrm{CO}_{2} \mathrm{co}-$ polymer in the bromination. Intrinsic viscosity in benzene solution of the $\mathrm{BMO}-\mathrm{CO}_{2}$ copolymer also decreased following bromination (Table II, Run 1).

Since the copolymerization of carbon dioxide and epoxide with a substituent containing halogen, such as epichlorophydrin, has been difficult so far, ${ }^{1}$ the procedure reported here is a good method for the introduction of a halogen to an epoxide $-\mathrm{CO}_{2}$ copolymer.

In an attempt to introduce an acetyl group to the brominated copolymer, the reaction of the co- polymer in acetonitrile with potassium acetate was carried out in the presence of $1,4,7,10,13,16-$ hexaoxacyclooctadecane (18-crown-6) at room temperature for $24 \mathrm{~h}$. This, however, resulted in the formation of cyclic carbonate. The attempted quaternization of the brominated copolymer with a large amount of triethylamine in chloroform also gave cyclic carbonate.

\section{Synthesis of Polymer-Metal Complex}

A wide variety of platinum (II) complexes has been investigated for use as antitumor drugs. ${ }^{9}$ Taking advantage of the pendant olefinic group of the BMO- $\mathrm{CO}_{2}$ copolymer, the synthesis of a polycarbonate having a platinum complex at the side chain was carried out, to obtain a polymer-drug combination which would slowly release platinum complex by the biochemical hydrolysis of the carbonate linkage of the main chain. ${ }^{10}$

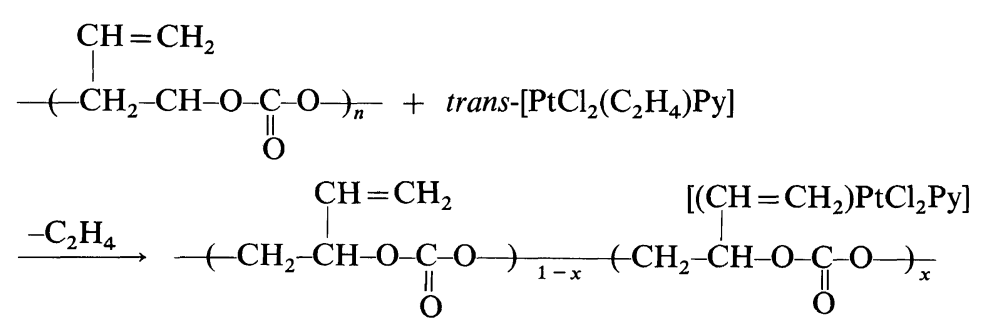

The polymer having a pendant platinum (II) complex was prepared by treating trans-dichloro(pyridine)(ethylene)platinum (II) ${ }^{7,8}$ with $\mathrm{BMO}-\mathrm{CO}_{2}$ copolymer in a chloroform solution at room temperature for $3 \mathrm{~h}$. The product obtained was insoluble in chloroform, benzene, dichloromethane and neutral water, but was soluble in $0.01 \mathrm{~N}$ aqueous ammonia. In this product, platinum is considered at least to some extent to be coordinated with the pendant vinyl group, since the formation of ethylene was detected in the gaseous phase of the reaction mixture by gas liquid chromatography.

Acknowledgement. One of the authors, Y. Yoshida, is grateful to The Sakkokai Foundation for providing a scholarship.

\section{REFERENCES}

1. S. Inoue, Chem. Technol., 6, 588 (1976); S. Inoue, Prog. Polym. Sci. Jpn., 8, 1 (1975).
2. S. Inoue, H. Koinuma, and T. Tsuruta, J. Polym. Sci., B, 7, 287 (1969); Makromol. Chem., 130, 210 (1969).

3. S. Inoue, K. Matsumoto, and Y. Yoshida, Makromol. Chem., 181, 2287 (1980).

4. S. Inoue, J. Macromol. Sci., Chem., A13, 651 (1979).

5. S. Winstein and H. J. Lucas, J. Am. Chem. Soc., 61, 1580 (1939); D. B. Bigley, C. Brown, and R. H. Weatherhead, J. Chem. Soc., Perkin II, 701, (1976).

6. S. Inoue, H. Koinuma, and T. Tsuruta, Polym. J., 2, 220 (1971).

7. W. MacNevin, A. Giddings, and A. Foris, Chem. Ind. (London), 557 (1958).

8. P. J. Busse, B. Greene, and M. Orchin, Inorg. Synth., 20, 180 (1979).

9. B. Rosenberg, L. VanCamp, J. E. Trosko, and V. H. Mansour, Nature, 222, 385 (1969); M. J. Cleare, and J. D. Hoeschele, Bioinorganic Chem., 2, 187 (1973).

10. S. Inoue, Y. Nomura, and Y. Yoshida, Polym. Prep. Jpn., 29, 143 (1980); Y. Yoshida, M. Takanashi, Y. Nomura, and S. Inoue, ibid., 29, 979 (1980); M. Takanashi, Y. Yoshida, and S. Inoue, ibid., 30, 133, 1412 (1981). 